\title{
Effective inter-electron interaction for metallic slab
}

\author{
Kostrobij P., Markovych B. \\ Lviv Polytechnic National University \\ 12 S. Bandera str., 79013, Lviv, Ukraine
}

(Received 15 Juny 2016)

\begin{abstract}
A system of electrons in a metal slab, which is described by the jellium model, is considered. The potential that forms a surface of the slab is modeled by the infinite square well potential. By using some approximations, the analytical expressions for effective interelectron interaction inside the slab and outside it are obtained.
\end{abstract}

Keywords: slab, effective interaction, correlator.

2000 MSC: $82 \mathrm{~B} 24$

UDC: 530.145

\section{Introduction}

The development of nanotechnologies involving deposition of metals on substrates requires further theoretical development and understanding of effects related to the electronic structure of nanoclusters and nanofilms. If the size of nanostructure is comparable with the corresponding electron Fermi wavelength, various physical properties are size dependence [1-3]. For metal nanofilms, many physical quantities, such as thermodynamic stability, electrical resistivity, superconducting critical temperature, the perpendicular upper critical field, surface adhesion, thermal-expansion coefficient, surface free energy, surface diffusion barriers, surface adsorption energy, work function, etc., oscillate as a function of film thickness [4].

The main problem of the statistical theory of such systems is the calculation of thermodynamic and statistical distribution functions. Using the functional integration method for such calculations allows us to get expansions for these characteristics, the basis for the construction of which is the effective interaction potential $[5,6]$. This potential satisfies the integral equation of convolution, analytical solving of which is a difficult problem [7].

In Refs. [8-10], the problem of determining screened potentials of electron interaction in such thin films is considered. This problem is solved with neglecting of frequency dispersion [8] or spatial dispersion [9] of screened potential. In Ref. [10], analytical expressions for the screened potentials of classic systems such as thin films are found within constant density approximation.

In this paper, the problem of determining the effective inter-electron interaction for metal slab in the quantum case is considered. The analytical expressions for this interaction both in the slab and, in contrast to Ref. [7], beyond it. In the case of increasing of the slab thickness, obtained results go over to results of Ref. [12].

\section{Model}

We consider a metal slab with the thickness $L$, which is laid along the $z$ axis, and two sides with the area $S(S \rightarrow \infty)$ are parallel to the $x y$ plane. We consider that one side of slab coincides with the $x y$ plane, i.e., is specified by the equation $z=0$, and the other parallel side is described by the equation $z=L$. 


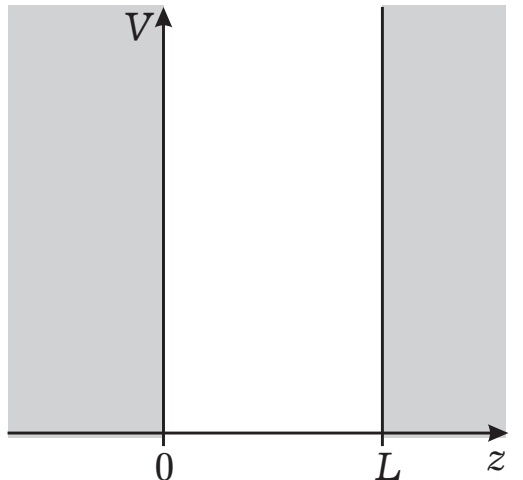

Fig. 1.

This slab is considered within the jellium model. Then the electron motion in a plane that is parallel to the $x y$ plane is free, and the motion along the $z$ axis is determined by the potential $V(z)$, which depends on the normal to the slab sides coordinate of the electron only. This potential is modelled by the infinite square well potential (see Fig. 1):

$$
V(z)= \begin{cases}0, & 0<z<L \\ \infty, & z \leqslant 0, z \geqslant L .\end{cases}
$$

The single-particle wave functions and the corresponding energies of the electron in the field of this potential can be written as

$$
\Psi_{\mathbf{k}_{\|}, \alpha}\left(\mathbf{r}_{\|}, z\right)=\frac{1}{\sqrt{S}} \mathrm{e}^{\mathrm{i} \mathbf{k}_{\| \mid} \mathbf{r}_{\|}} \varphi_{\alpha}(z), \quad E_{\alpha}\left(\mathbf{k}_{\|}\right)=\frac{\hbar^{2} k_{\|}^{2}}{2 m}+\varepsilon_{\alpha}
$$

where $\mathbf{r}_{\|}$is the two-dimensional coordinate of the electron in the $x y$ plane, $\mathbf{k}_{\|}$is the wave vector of the electron in the $x y$ plane. The functions $\varphi_{\alpha}(z)$ satisfy the one-dimensional stationary Schrödinger equation

$$
\left[-\frac{\hbar^{2}}{2 m} \frac{\mathrm{d}^{2}}{\mathrm{~d} z^{2}}+V(z)\right] \varphi_{\alpha}(z)=\varepsilon_{\alpha} \varphi_{\alpha}(z)
$$

and have the form

$$
\varphi_{\alpha}(z)=\sqrt{\frac{2}{L}} \sin (\alpha z) \theta(z) \theta(L-z),
$$

where $m$ is the electron mass, $\theta(z)$ is the Heaviside step function, $\varepsilon_{\alpha}=\frac{\hbar^{2} \alpha^{2}}{2 m}, \alpha=\frac{\pi n}{L}, n=1,2, \ldots$

\section{Effective inter-electron interaction}

\subsection{Integral equation for effective inter-electron interaction}

In the case of low temperatures, the two-dimensional Fourier transform of the effective inter-electron interaction is a solution of the integral equation $[11,12]$

$$
g\left(q \mid z_{1}, z_{2}\right)=\nu\left(q \mid z_{1}-z_{2}\right)+\frac{\beta}{S L^{2}} \int_{-\infty}^{+\infty} \mathrm{d} z \int_{-\infty}^{+\infty} \mathrm{d} z^{\prime} \nu\left(q \mid z_{1}-z\right) \mathfrak{M}\left(q \mid z, z^{\prime}\right) g\left(q \mid z^{\prime}, z_{2}\right),
$$

where $\beta$ is the reciprocal of the thermodynamic temperature, $\nu\left(q \mid z_{1}-z_{2}\right)=\frac{2 \pi e^{2}}{q} \mathrm{e}^{-q\left|z_{1}-z_{2}\right|}$ is the twodimensional Fourier transform of the Coulomb interaction, $\mathfrak{M}\left(q \mid z, z^{\prime}\right)$ is the two-particle correlator in the case of low temperatures,

$$
\begin{gathered}
\mathfrak{M}\left(q \mid z, z^{\prime}\right)=\frac{L^{2}}{\beta} \sum_{\alpha_{1}, \alpha_{2}} \Lambda_{\alpha_{1}, \alpha_{2}}(q) \varphi_{\alpha_{1}}^{*}(z) \varphi_{\alpha_{2}}(z) \varphi_{\alpha_{2}}^{*}\left(z^{\prime}\right) \varphi_{\alpha_{1}}\left(z^{\prime}\right), \\
\Lambda_{\alpha_{1}, \alpha_{2}}(q)=\sum_{\mathbf{k}_{\|}} \Pi_{\alpha_{1}, \alpha_{2}}\left(\mathbf{k}_{\|}, \mathbf{q}\right) \\
\Pi_{\alpha_{1}, \alpha_{2}}\left(\mathbf{k}_{\|}, \mathbf{q}\right)=\frac{\theta\left(\mu-E_{\alpha_{1}}\left(\mathbf{k}_{\|}\right)\right)-\theta\left(\mu-E_{\alpha_{2}}\left(\mathbf{k}_{\|}-\mathbf{q}\right)\right)}{E_{\alpha_{1}}\left(\mathbf{k}_{\|}\right)-E_{\alpha_{2}}\left(\mathbf{k}_{\|}-\mathbf{q}\right)}
\end{gathered}
$$

$\mu$ is the chemical potential. 
In the mirror electron scattering approximation [12] $\Lambda_{\alpha_{1}, \alpha_{2}}(q) \approx \Lambda_{\alpha_{1}, \alpha_{1}}(q)$, taking the summation over $\alpha_{2}$ we get

$$
\begin{aligned}
\mathfrak{M}\left(q \mid z, z^{\prime}\right)= & -\frac{L^{2}}{\beta} \frac{2 m}{\hbar^{2}} \frac{S}{2 \pi} \sum_{\alpha}\left|\varphi_{\alpha}(z)\right|^{2} \\
& \times\left[1-\sqrt{1-4 \frac{k_{\mathrm{F}}^{2}-\alpha^{2}}{q^{2}}} \theta\left(1-4 \frac{k_{\mathrm{F}}^{2}-\alpha^{2}}{q^{2}}\right)\right] \theta\left(k_{\mathrm{F}}-\alpha\right) \delta\left(z-z^{\prime}\right),
\end{aligned}
$$

where $k_{\mathrm{F}}$ is the magnitude of the Fermi wave vector, $k_{\mathrm{F}}=\frac{\sqrt{2 m \mu}}{\hbar}$.

For further simplify the expression (6), we use the constant density approach [12]. Then the integral equation (4) is greatly simplified,

$$
g\left(q \mid z_{1}, z_{2}\right)=\nu\left(q \mid z_{1}-z_{2}\right)-\frac{\varkappa^{2}(q)}{4 \pi e^{2}} \int_{0}^{L} \mathrm{~d} z \nu\left(q \mid z_{1}-z\right) g\left(q \mid z, z_{2}\right),
$$

where

$$
\varkappa^{2}(q)=4 \pi e^{2} \frac{2 m}{\hbar^{2}} \frac{1}{2 \pi L} \sum_{\alpha}\left[1-\sqrt{1-4 \frac{k_{\mathrm{F}}^{2}-\alpha^{2}}{q^{2}}} \theta\left(1-4 \frac{k_{\mathrm{F}}^{2}-\alpha^{2}}{q^{2}}\right)\right] \theta\left(k_{\mathrm{F}}-\alpha\right) .
$$

\subsection{Analytical solution of integral equation for effective inter-electron interaction}

The integral equation (7) can be solved analytically. For this purpose, we reduce this integral equation to a boundary value problem. Let us differentiate twice this integral equation with respect to variable $z_{1}$. Taking into account that

$$
\begin{gathered}
\frac{\mathrm{d} \nu\left(q \mid z_{1}-z_{2}\right)}{\mathrm{d} z_{1}}=-q \nu\left(q \mid z_{1}-z_{2}\right) \operatorname{sign}\left(z_{1}-z_{2}\right), \\
\frac{\mathrm{d}^{2} \nu\left(q \mid z_{1}-z_{2}\right)}{\mathrm{d} z_{1}^{2}}=q^{2} \nu\left(q \mid z_{1}-z_{2}\right)-4 \pi e^{2} \delta\left(z_{1}-z_{2}\right),
\end{gathered}
$$

we get

$$
\begin{aligned}
\frac{\mathrm{d} g\left(q \mid z_{1}, z_{2}\right)}{\mathrm{d} z_{1}}= & -q \nu\left(q \mid z_{1}-z_{2}\right) \operatorname{sign}\left(z_{1}-z_{2}\right) \\
& +\frac{\varkappa^{2}(q)}{4 \pi e^{2}} q \int_{0}^{L} \mathrm{~d} z \nu\left(q \mid z_{1}-z\right) \operatorname{sign}\left(z_{1}-z\right) g\left(q \mid z, z_{2}\right), \\
& {\left[\frac{\mathrm{d}^{2}}{\mathrm{~d} z_{1}^{2}}-q^{2}-\varkappa^{2}(q) \theta\left(z_{1}\right) \theta\left(L-z_{1}\right)\right] g\left(q \mid z_{1}, z_{2}\right)=-4 \pi e^{2} \delta\left(z_{1}-z_{2}\right) . }
\end{aligned}
$$

For solving the differential equation (9), we divide the domain of normal coordinates of two electrons $z_{1} z_{2}$ into nine domains, as it is shown in Fig. 2, and consistently we find solution in the each domain.

In the domain I, the differential equations (9) takes the form

$$
\left(\frac{\mathrm{d}^{2}}{\mathrm{~d} z_{1}^{2}}-Q^{2}\right) g\left(q \mid z_{1}, z_{2}\right)=-4 \pi e^{2} \delta\left(z_{1}-z_{2}\right), \quad 0<z_{1}<L, 0 \leqslant z_{2} \leqslant L,
$$




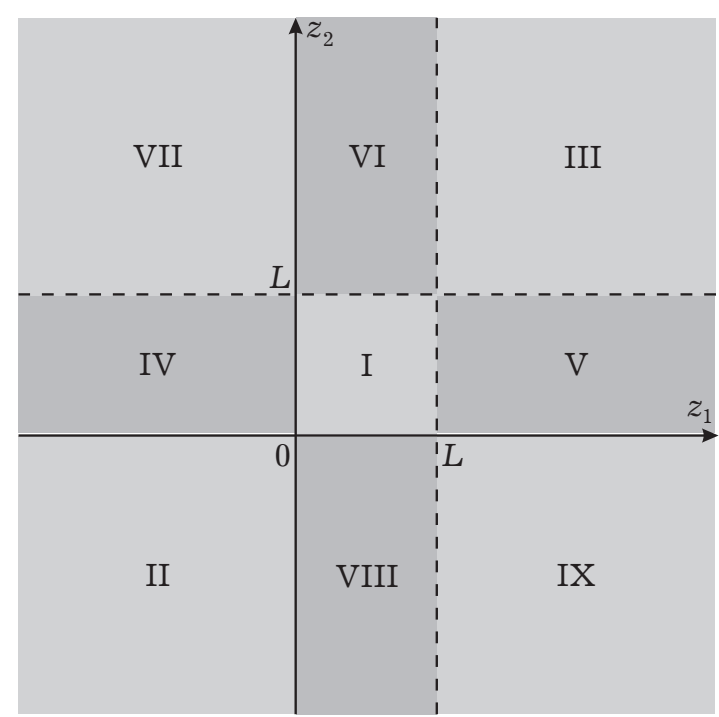

Fig. 2.

where $Q^{2}=q^{2}+\varkappa^{2}(q)$. From Eq. (8) we obtain two following boundary conditions

$$
\begin{aligned}
& \left.\left(\frac{\mathrm{d}}{\mathrm{d} z_{1}}-q\right) g\left(q \mid z_{1}, z_{2}\right)\right|_{z_{1}=0}=0, \quad 0 \leqslant z_{2} \leqslant L, \\
& \left.\left(\frac{\mathrm{d}}{\mathrm{d} z_{1}}+q\right) g\left(q \mid z_{1}, z_{2}\right)\right|_{z_{1}=L}=0, \quad 0 \leqslant z_{2} \leqslant L .
\end{aligned}
$$

A solution of the boundary value problem (10)-(12) is found analytically and it has the form

$$
\begin{aligned}
g\left(q \mid z_{1}, z_{2}\right)= & \frac{2 \pi e^{2}}{Q} \frac{1}{1-\left(\frac{Q-q}{Q+q}\right)^{2} \mathrm{e}^{-2 Q L}}\left[\mathrm{e}^{-Q\left|z_{1}-z_{2}\right|}+\left(\frac{Q-q}{Q+q}\right)^{2} \mathrm{e}^{-Q\left(2 L-\left|z_{1}-z_{2}\right|\right)}\right. \\
& \left.+\frac{Q-q}{Q+q}\left(\mathrm{e}^{-Q\left(z_{1}+z_{2}\right)}+\mathrm{e}^{-Q\left(2 L-z_{1}-z_{2}\right)}\right)\right]
\end{aligned}
$$

In the domain II, the differential equation (9) has the form

$$
\left(\frac{\mathrm{d}^{2}}{\mathrm{~d} z_{1}^{2}}-q^{2}\right) g\left(q \mid z_{1}, z_{2}\right)=-4 \pi e^{2} \delta\left(z_{1}-z_{2}\right), \quad z_{1}<0, z_{2} \leqslant 0 .
$$

From Eq. (8) we get the boundary condition

$$
\left.\left(\frac{\mathrm{d}}{\mathrm{d} z_{1}}-q\right) g\left(q \mid z_{1}, z_{2}\right)\right|_{z_{1}=0}=-4 \pi e^{2} \mathrm{e}^{q z_{2}}, \quad z_{2} \leqslant 0 .
$$

With this condition, the finiteness condition of solution, and the continuity condition of solution at the origin, the solution of the boundary value problem $(14),(15)$ is found analytically,

$$
\begin{aligned}
g\left(q \mid z_{1}, z_{2}\right)= & \frac{2 \pi e^{2}}{q}\left(\mathrm{e}^{-q\left|z_{1}-z_{2}\right|}-\mathrm{e}^{q\left(z_{1}+z_{2}\right)}\right) \\
& +\frac{4 \pi e^{2}}{Q+q} \frac{1+\frac{Q-q}{Q+q} \mathrm{e}^{-2 Q L}}{1-\left(\frac{Q-q}{Q+q}\right)^{2} \mathrm{e}^{-2 Q L}} \mathrm{e}^{q\left(z_{1}+z_{2}\right)} .
\end{aligned}
$$


In the domain III, the differential equations (9) takes the form

$$
\left(\frac{\mathrm{d}^{2}}{\mathrm{~d} z_{1}^{2}}-q^{2}\right) g\left(q \mid z_{1}, z_{2}\right)=-4 \pi e^{2} \delta\left(z_{1}-z_{2}\right), \quad z_{1}>L, z_{2} \geqslant L .
$$

From Eq. (8) we obtain the boundary condition

$$
\left.\left(\frac{\mathrm{d}}{\mathrm{d} z_{1}}+q\right) g\left(q \mid z_{1}, z_{2}\right)\right|_{z_{1}=L}=-4 \pi e^{2} \mathrm{e}^{q\left(L-z_{2}\right)}, \quad z_{2} \geqslant L .
$$

With this condition, the finiteness condition of solution, and the continuity condition of solution at the point $(L, L)$, the solution of the boundary value problem (17), (18) is found analytically,

$$
\begin{aligned}
g\left(q \mid z_{1}, z_{2}\right)= & \frac{2 \pi e^{2}}{q}\left(\mathrm{e}^{-q\left|z_{1}-z_{2}\right|}-\mathrm{e}^{-q\left(z_{1}+z_{2}-2 L\right)}\right) \\
& +\frac{4 \pi e^{2}}{Q+q} \frac{1+\frac{Q-q}{Q+q} \mathrm{e}^{-2 Q L}}{1-\left(\frac{Q-q}{Q+q}\right)^{2} \mathrm{e}^{-2 Q L}} \mathrm{e}^{-q\left(z_{1}+z_{2}-2 L\right)} .
\end{aligned}
$$

In the domain IV, the differential equation (9) has the form

$$
\left(\frac{\mathrm{d}^{2}}{\mathrm{~d} z_{1}^{2}}-q^{2}\right) g\left(q \mid z_{1}, z_{2}\right)=0, \quad z_{1}<0,0 \leqslant z_{2} \leqslant L .
$$

From Eq. (8) we get the boundary condition

$$
\left.\left(\frac{\mathrm{d}}{\mathrm{d} z_{1}}-q\right) g\left(q \mid z_{1}, z_{2}\right)\right|_{z_{1}=0}=0, \quad 0 \leqslant z_{2} \leqslant L
$$

which is satisfied automatically for all solutions of the differential equations (20). With the finiteness condition of solution, and the continuity condition of solution at $z_{1}=0$, the solution of Eq. (20) is found analytically,

$$
g\left(q \mid z_{1}, z_{2}\right)=\frac{4 \pi e^{2}}{Q+q} \frac{1}{1-\left(\frac{Q-q}{Q+q}\right)^{2} \mathrm{e}^{-2 Q L}}\left[\mathrm{e}^{q z_{1}-Q z_{2}}+\frac{Q-q}{Q+q} \mathrm{e}^{q z_{1}-Q\left(2 L-z_{2}\right)}\right] .
$$

In the domain $\mathrm{V}$, the differential equations (9) takes the form

$$
\left(\frac{\mathrm{d}^{2}}{\mathrm{~d} z_{1}^{2}}-q^{2}\right) g\left(q \mid z_{1}, z_{2}\right)=0, \quad z_{1}>L, 0 \leqslant z_{2} \leqslant L .
$$

From Eq. (8) we obtain the boundary condition

$$
\left.\left(\frac{\mathrm{d}}{\mathrm{d} z_{1}}+q\right) g\left(q \mid z_{1}, z_{2}\right)\right|_{z_{1}=L}=0, \quad 0 \leqslant z_{2} \leqslant L
$$

which is satisfied automatically for all solutions of the differential equations (23). With the finiteness condition of solution, and the continuity condition of solution at $z_{1}=L$, the solution of Eq. (23) is found analytically,

$$
g\left(q \mid z_{1}, z_{2}\right)=\frac{4 \pi e^{2}}{Q+q} \frac{1}{1-\left(\frac{Q-q}{Q+q}\right)^{2} \mathrm{e}^{-2 Q L}}\left[\mathrm{e}^{-q\left(z_{1}-L\right)-Q\left(L-z_{2}\right)}+\frac{Q-q}{Q+q} \mathrm{e}^{-q\left(z_{1}-L\right)-Q\left(L+z_{2}\right)}\right] .
$$


In the domain VI, the differential equation (9) has the form

$$
\left(\frac{\mathrm{d}^{2}}{\mathrm{~d} z_{1}^{2}}-Q^{2}\right) g\left(q \mid z_{1}, z_{2}\right)=0, \quad 0<z_{1}<L, z_{2} \geqslant L .
$$

From Eq. (8) we get two following boundary conditions

$$
\begin{aligned}
& \left.\left(\frac{\mathrm{d}}{\mathrm{d} z_{1}}-q\right) g\left(q \mid z_{1}, z_{2}\right)\right|_{z_{1}=0}=0, \quad z_{2} \geqslant L \\
& \left.\left(\frac{\mathrm{d}}{\mathrm{d} z_{1}}+q\right) g\left(q \mid z_{1}, z_{2}\right)\right|_{z_{1}=L}=2 q \nu\left(q \mid L-z_{2}\right), \quad z_{2} \geqslant L .
\end{aligned}
$$

A solution of the boundary value problem (26)-(28) is found analytically and it has the form

$$
g\left(q \mid z_{1}, z_{2}\right)=\frac{4 \pi e^{2}}{Q+q} \frac{1}{1-\left(\frac{Q-q}{Q+q}\right)^{2} \mathrm{e}^{-2 Q L}}\left[\mathrm{e}^{-Q\left(L-z_{1}\right)-q\left(z_{2}-L\right)}+\frac{Q-q}{Q+q} \mathrm{e}^{-Q\left(L+z_{1}\right)-q\left(z_{2}-L\right)}\right],
$$

and it is continuous at the point $z_{1}=L$.

In the domain VII, the differential equations (9) takes the form

$$
\left(\frac{\mathrm{d}^{2}}{\mathrm{~d} z_{1}^{2}}-q^{2}\right) g\left(q \mid z_{1}, z_{2}\right)=0, \quad z_{1}<0, z_{2} \geqslant L
$$

From Eq. (8) we obtain the boundary condition

$$
\left.\left(\frac{\mathrm{d}}{\mathrm{d} z_{1}}-q\right) g\left(q \mid z_{1}, z_{2}\right)\right|_{z_{1}=0}=0, \quad z_{2} \geqslant L
$$

which is satisfied automatically for all solutions of the differential equations (30). With the finiteness condition of solution, and the continuity condition of solution at $z_{1}=0$, the solution of Eq. (30) is found analytically,

$$
g\left(q \mid z_{1}, z_{2}\right)=\frac{4 \pi e^{2}}{Q+q} \frac{\frac{2 Q}{Q+q} \mathrm{e}^{-Q L}}{1-\left(\frac{Q-q}{Q+q}\right)^{2} \mathrm{e}^{-2 Q L}} \mathrm{e}^{q z_{1}-q\left(z_{2}-L\right)} .
$$

In the domain VIII, the differential equation (9) has the form

$$
\left(\frac{\mathrm{d}^{2}}{\mathrm{~d} z_{1}^{2}}-Q^{2}\right) g\left(q \mid z_{1}, z_{2}\right)=0, \quad 0<z_{1}<L, z_{2} \leqslant 0 .
$$

From Eq. (8) we get the boundary condition

$$
\begin{aligned}
& \left.\left(\frac{\mathrm{d}}{\mathrm{d} z_{1}}-q\right) g\left(q \mid z_{1}, z_{2}\right)\right|_{z_{1}=0}=-2 q \nu\left(q \mid-z_{2}\right), \quad z_{2} \leqslant 0 \\
& \left.\left(\frac{\mathrm{d}}{\mathrm{d} z_{1}}+q\right) g\left(q \mid z_{1}, z_{2}\right)\right|_{z_{1}=L}=0, \quad z_{2} \leqslant 0
\end{aligned}
$$

A solution of the boundary value problem (33)-(35) is found analytically and it has the form

$$
g\left(q \mid z_{1}, z_{2}\right)=\frac{4 \pi e^{2}}{Q+q} \frac{1}{1-\left(\frac{Q-q}{Q+q}\right)^{2} \mathrm{e}^{-2 Q L}}\left[\mathrm{e}^{-Q z_{1}+q z_{2}}+\frac{Q-q}{Q+q} \mathrm{e}^{Q\left(z_{1}-2 L\right)+q z_{2}}\right],
$$


and it is continuous at the point $z_{1}=0$.

In the domain IX, the differential equations (9) takes the form

$$
\left(\frac{\mathrm{d}^{2}}{\mathrm{~d} z_{1}^{2}}-q^{2}\right) g\left(q \mid z_{1}, z_{2}\right)=0, \quad z_{1}>L, z_{2} \leqslant 0
$$

From Eq. (8) we obtain the boundary condition

$$
\left.\left(\frac{\mathrm{d}}{\mathrm{d} z_{1}}+q\right) g\left(q \mid z_{1}, z_{2}\right)\right|_{z_{1}=L}=0, \quad z_{2} \leqslant 0
$$

which is satisfied automatically for all solutions of the differential equations (37). With the finiteness condition of solution, and the continuity condition of solution at $z_{1}=L$, the solution of Eq. (37) is found analytically,

$$
g\left(q \mid z_{1}, z_{2}\right)=\frac{4 \pi e^{2}}{Q+q} \frac{\frac{2 Q}{Q+q} \mathrm{e}^{-Q L}}{1-\left(\frac{Q-q}{Q+q}\right)^{2} \mathrm{e}^{-2 Q L}} \mathrm{e}^{-q\left(z_{1}-L\right)+q z_{2}} .
$$

It should be noted that increasing the thickness of the slab to infinity leads to disappearance of the domains III, V, VI, VII, and IX, and the effective inter-electron interaction in the domains I, II, IV, and VIII are transformed to the well-known expressions [12],

$$
\begin{gathered}
g\left(q \mid z_{1} \geqslant 0, z_{2} \geqslant 0\right)=\frac{2 \pi e^{2}}{Q}\left[\mathrm{e}^{-Q\left|z_{1}-z_{2}\right|}+\frac{Q-q}{Q+q} \mathrm{e}^{-Q\left(z_{1}+z_{2}\right)}\right], \\
g\left(q \mid z_{1} \leqslant 0, z_{2} \leqslant 0\right)=\frac{2 \pi e^{2}}{q}\left[\mathrm{e}^{-q\left|z_{1}-z_{2}\right|}-\frac{Q-q}{Q+q} \mathrm{e}^{q\left(z_{1}+z_{2}\right)}\right], \\
g\left(q \mid z_{1} \leqslant 0, z_{2} \geqslant 0\right)=\frac{4 \pi e^{2}}{Q+q} \mathrm{e}^{q z_{1}-Q z_{2}}, \\
g\left(q \mid z_{1} \geqslant 0, z_{2} \leqslant 0\right)=\frac{4 \pi e^{2}}{Q+q} \mathrm{e}^{-Q z_{1}+q z_{2}} .
\end{gathered}
$$

\section{Conclusion}

The problem of finding of the effective inter-electron interaction for the metallic slab is considered. This interaction is a solution of the integral equation, which in general should be solved numerically. However, by using the constant density approach for $\left|\varphi_{\alpha}(z)\right|^{2}$, the integral equation can be reduced to nine boundary value problems that can be solved analytically. In the paper, these boundary value problems are solved analytically, and the obtained solutions are continuous at the boundary edges of the domains. Forms of these solutions shows that the image forces relative the planes, which limit the metallic slab, $z=0$, and $z=L$, are taken into account in the effective inter-electron interaction.

[1] Cohen M. L., Knight W. D. The Physics of Metal Clusters. Phys. Today. 43(12), 42-50 (1990).

[2] de Heer W. A. The physics of simple metal clusters: experimental aspects and simple models. Rev. Mod. Phys. 65, n. 3, 611-676 (1993).

[3] Brack M. The physics of simple metal clusters: self-consistent jellium model and semiclassical approaches. Rev. Mod. Phys. 65, n. 3, 677-732 (1993).

[4] Han Y., Liu D.-J. Quantum size effects in metal nanofilms: Comparison of an electron-gas model and density functional theory calculations. Phys. Rev. B. 80, 155404-1-155404-17 (2009).

Mathematical Modeling and Computing, Vol. 3, No. 1, pp. 51-58 (2016) 
[5] Kostrobii P. P., Markovych B. M. Statistical theory of the spacebounded systems of charged fermi-particles: I. The functional integration method and effective potentials. J. Phys. Stud. 7, 195-206 (2003).

[6] Kostrobii P. P., Markovych B. M. A statistical theory of the spacebounded systems of charged fermiparticles: II. Distribution functions. J. Phys. Stud. 7, 298-312 (2003).

[7] Kuryliak I. J., Kostroby P. P., Pizio A. A. Screened Potentials of Electron Interaction in Space-Bounded Systems. Preprint ITF-87-7P (1987), (in Russian).

[8] Ilchenko L. G., Pashickij Ye. A., Romanov Yu. A. Elektrostaticheskij potencial zarjadov v sloistyh sistemah s prostranstvennoj dispersiej. Fiz. tv. tela. 22(9), 2700-2710 (1980), (in Russian).

[9] Vojtenko A. I., Gabovich A. M., Rozenbaum V. M. Dinamicheskaya polyarizaciya metalla pri polevoj emisii. Preprint In-t fiziki n. 17 (1984), (in Russian).

[10] Usenko A. S. Prostranstvennye korrelyacii zaryazhennyh chastic v plazmennom sloe. Ukr. fiz. zhurn. 28(6), 839-847 (1983), (in Russian).

[11] Kostrobij P. P., Markovych B. M. A new approach to calculate the thermodynamic potential of an inhomogeneous electron gas. Condens. Matter Phys. 6, n. 2(34), 347-362 (2003).

[12] Kostrobij P. P., Markovych B. M. An effective potential of electron-electron interaction in semi-infinite jellium. Condens. Matter Phys. 9, n. 4(48), 747-756 (2006).

\title{
Ефективний потенціал міжелектронної взаємодії для металевої плівки
}

\author{
Костробій П. П., Маркович Б. М. \\ Національний університет «Лъвівсъка політехніка» \\ вул. С. Бандери, 12, Львів, 79013
}

Розглянуто систему електронів у металевій плівці, яка описується моделлю «желе». Потенціал, який формує поверхні плівки, змодельовано безмежно високою прямокутною потенціальною ямою. Використовуючи деякі наближення, отримано аналітичні вирази для ефективного потенціалу міжелектронної взаємодії як всередині плівки, так і поза нею.

Ключові слова: плівка, ефективний потенціал, кореляційна функція.

2000 MSC: $82 \mathrm{~B} 24$

UDC: 530.145

Mathematical Modeling and Computing, Vol.3, No.1, pp. 51-58 (2016) 